\title{
Factors associated with developmental progress of full term neonates who required intensive
}

\section{care}

\author{
L LUDMAN, R LANSDOWN, AND L SPITZ \\ Institute of Child Health, Hospital for Sick Children, Great Ormond Street, London
}

SUMmaRY The development of 43 infants born at full term, who were admitted to neonatal intensive care units shortly after birth, was compared in a prospective longitudinal study with that of a group of 29 healthy newborn babies. Thirty infants required emergency operations during the neonatal period, and 13 were admitted for medical reasons. The effects of being in hospital and being separated from their mothers were also studied. At 1 year the 'sick' babies were performing significantly less well in almost all areas of development. In the group of sick infants, the mothers' mental health explained $25 \%$ of the variance in developmental outcome at 6 months. At 1 year the most important predictor was length of stay in hospital, which explained $35 \%$ of the variance.

The developmental outcome of infants who were premature, small for gestational age, of low birth weight, and more recently of very low birth weight (VLBW) has been the focus of extensive psychological research, ${ }^{1-8}$ and it is well established that preterm babies have more mental and behavioural problems in childhood than infants born at full term. ${ }^{8}$ An important group of sick newborn babies are those born at full term who require intensive care for conditions that may necessitate either emergency operations or intensive medical treatment. These babies and their families experience many of the problems associated with prematurity, but we know of no previous study of their developmental outcome. A three year prospective longitudinal study is being carried out to examine the intellectual, social, and emotional development of two groups of sick infants born at full term. The main group comprises 30 infants admitted for emergency operations within the neonatal period, and a smaller group of 13 infants who required intensive medical care at birth. In this paper we report their developmental progress up to the age of 1 year.

\section{Patients and methods}

The study group of sick infants comprised 43 newborn infants born at full term. Thirty were admitted to the neonatal surgical unit at the
Hospital for Sick Children, Great Ormond Street, during the period November 1983 to December 1984, and 13 were admitted for neonatal intensive care either to the same hospital or to Queen Charlotte's Maternity Hospital (table 1). Twenty nine healthy newborn infants were matched with the surgical group for sex, social group, mother's age and marital status, birth order, and geographical location, and these constitute the control group. This group was collected during the period December 1983 to October 1985. There were no significant differences between the groups for sex, social group, birth order, or mother's age or marital status (table 2).

A standardised assessment of the severity of each infant's condition was made using the Parmelee postnatal complication scale, ${ }^{9}$ which assesses the infant's postnatal course within the first month of life, and includes conditions that reflect an increased risk of mortality and morbidity such as ventilation and metabolic disturbance. The possible range of scores is from 55 to 160 with higher scores having a better prognosis. The median score for the sick babies was 77 (range 55-87).

The birth weights of 41 of the sick babies were between 2000-4500 g. One baby with hydrops weighed more than $4500 \mathrm{~g}$, and one who was small for gestational age weighed $1980 \mathrm{~g}$. Gestational age was equal to or greater than 37 weeks. Fourteen $(33 \%)$ required ventilation, and of these $10(23 \%)$ 
Table 1 Diagnoses in 43 children born at full term who required neonatal intensive care

\begin{tabular}{|c|c|c|}
\hline Diagnosis & $\begin{array}{l}\text { Total No } \\
\text { of children }\end{array}$ & $\begin{array}{l}\text { No with } \\
\text { multiple } \\
\text { abnormalities }\end{array}$ \\
\hline \multicolumn{3}{|l|}{ Surgical patients: } \\
\hline \multicolumn{3}{|l|}{$\begin{array}{l}\text { Oesophageal atresia and } \\
\text { tracheo-oesophageal }\end{array}$} \\
\hline Diaphragmatic hernia & 4 & 0 \\
\hline Anorectal abnormalities & 4 & 1 \\
\hline Necrotising enterocolitis & 4 & 1 \\
\hline Gastroschisis & 2 & 0 \\
\hline Meconium ileus & 2 & 1 \\
\hline Antral atresia & 1 & 0 \\
\hline Duodenal atresia & 1 & 1 \\
\hline Malrotation & 1 & 0 \\
\hline Ileal stenosis & 1 & 0 \\
\hline Hirschsprung's disease & 1 & 0 \\
\hline Nasal obstruction & 1 & 0 \\
\hline Wilms's tumour & 1 & 0 \\
\hline Sacrococcygeal teratoma & 1 & 0 \\
\hline Lumbar meningomyelocele & 1 & 0 \\
\hline \multicolumn{3}{|l|}{ Medical patients: } \\
\hline Pneumonia & 3 & $\mathbf{0}$ \\
\hline Necrotising enterocilitis & 2 & 0 \\
\hline Respiratory distress & 2 & 0 \\
\hline Congenital infection & 1 & $\mathbf{0}$ \\
\hline Meningitis & 1 & 0 \\
\hline Hydrops & 1 & 0 \\
\hline Birth asphyxia & 1 & 0 \\
\hline \multicolumn{3}{|l|}{ Pneumonitis and pulmonary } \\
\hline hypertension & 1 & $\mathbf{0}$ \\
\hline Aspiration syndrome & 1 & 0 \\
\hline
\end{tabular}

were ventilated for more than four days. The median duration of the first admission (including time spent in local hospitals) was 22 days (range 7-91). Seventeen were readmitted for varying lengths of time before the age of 6 months, and a further nine before the age of 1 year. The median length of stay in hospital by the age of 1 year was 28 days (range 7-365).

The families were studied intensively during the first year. The initial interview with the parent(s) took place in the hospital. All subsequent interviews and assessments (at 6 weeks, 6 months, and 1 year) were conducted in the family home. At each stage the mother was interviewed using a semistructured interview. This covered many aspects of family life and relationships, including the marital relationship, ${ }^{10}$ support, and stress factors. The mothers' mental health was assessed using Goldberg's standardised psychiatric interview ${ }^{11}$ and general health questionnaire. ${ }^{12}$ At 6 months and 1 year the Griffiths's mental development scales ${ }^{13}$ were used to assess the infants' development. The interviews and assessments were performed by. the research psychologist (LL) conducting the study.
Table 2 Demographic details of the two groups

\begin{tabular}{llr}
\hline & $\begin{array}{l}\text { No (\%) of } \\
\text { study group } \\
(n=43)\end{array}$ & $\begin{array}{l}\text { No (\%) of } \\
\text { control group } \\
(n=29)\end{array}$ \\
\hline $\begin{array}{l}\text { Sex: } \\
\quad \text { Male }\end{array}$ & $19(44)$ & $8(28)$ \\
$\quad$ Female & $23(56)$ & $21(72)$ \\
Social group: & & \\
$\quad$ Father non-manual worker & $21(49)$ & $13(45)$ \\
$\quad$ Father manual worker & $15(35)$ & $12(41)$ \\
$\quad$ Single mother & $7(16)$ & $4(14)$ \\
& & \\
$\begin{array}{l}\text { Marital status of mother: } \\
\quad \text { Married }\end{array}$ & $36(84)$ & $25(86)$ \\
Single & $7(16)$ & $4(14)$ \\
Mother's age: & & \\
$\quad<25$ & $14(33)$ & $14(48)$ \\
25 or more & $29(67)$ & $15(52)$ \\
Parity: & & \\
$\quad$ Primiparous & & \\
$\quad$ Multiparous & $23(53)$ & $15(52)$ \\
\hline
\end{tabular}

The Statistical Package for the Social Sciences (SPSS-X) multiple regression techniques were used to examine the association between possible predictors and developmental outcome. Where distributional characteristics dictated (for example, the distribution of length of stay in hospital) appropriate logarithmic transformations were made. The significance of differences between means was assessed by Student's $t$ test or one way analysis of variance, as appropriate, a $\mathrm{p}$ value of $<0.05$ being accepted as significant.

\section{Results}

DEVELOPMENTAL OUTCOME (GRIFFITHS'S SCALE)

There were no significant differences between the groups at 6 months. At 1 year there were significant differences in five of the seven Griffiths's scales (table 3). The mean general developmental quotient and mental age (weeks) of the sick infants were significantly lower than those of the control infants. In addition the sick infants scored significantly less well in hearing and speech, and had poorer fine motor control. Their locomotor development was also significantly slower.

\section{MENTAL HEALTH OF MOTHERS}

The degree of psychiatric morbidity as assessed by the general health questionnaire at 6 weeks, and by the standardised psychiatric interview at 1 year, was significantly greater among mothers of the sick infants than among the mothers of the control infants $(p=0.04$ and $p=0.02$, respectively, MannWhitney U test). 
Table 3 Developmental quotients in the two groups at the age of 1 year

\begin{tabular}{|c|c|c|c|}
\hline Griffiths's scales & $\begin{array}{l}\text { Mean }(S D) \text { score } \\
\text { in study group } \\
(n=41)^{*}\end{array}$ & $\begin{array}{l}\text { Mean }(S D) \text { score } \\
\text { in control group } \\
(n=27) \dagger\end{array}$ & p Value \\
\hline General quotient & $102 \cdot 92(15 \cdot 23)$ & $109 \cdot 11(7 \cdot 52)$ & 0.03 \\
\hline Mental age (weeks) & $54.99(8.14)$ & $58.35(4.39)$ & $0 \cdot 03$ \\
\hline Motor & $108 \cdot 19(24 \cdot 76)$ & $118.00(13.97)$ & $0 \cdot 04$ \\
\hline Personal/social & $101 \cdot 21(14 \cdot 77)$ & $102 \cdot 29(5.96)$ & $0 \cdot 67$ \\
\hline Hearing/speech & $94.43(16.90)$ & $100 \cdot 62(7 \cdot 14)$ & $0 \cdot 04$ \\
\hline Eye/hand & $105.53(13.64)$ & $113.74(9.69)$ & 0.005 \\
\hline Performance & $105 \cdot 39(17.03)$ & $111 \cdot 11(14 \cdot 95)$ & $0 \cdot 16$ \\
\hline
\end{tabular}

${ }^{*}$ One baby was severely subnormal and excluded from developmental testing and one baby was adopted. †Two families declined to continue.

The factors having the most influence on the development of the sick infants at 6 months were the mental state of the mother $(\beta=-0.498)$, length of stay in hospital $(\beta=-0.414)$, repeated stays in hospital $(\beta=-0.344)$, and postnatal complication scale scores $(\beta=0.332)$. Because the last three variables were strongly intercorrelated, length of stay in hospital (the variable most strongly associated with developmental outcome), was used as the main predictor in multivariate regression analyses. SPSS-X stepwise regression showed that $25 \%$ of the variability in the general quotient was explained by the mothers' mental health scores $(F(1,41) 13.49$, $\mathrm{p}<0.001)$. When length of stay in hospital was forced into a standard regression analysis first, it explained $17 \%$ of the variance $(F(1,41) 8.49$, $\mathrm{p}=\mathbf{0 . 0 0 6 )}$. These two variables in combination contributed $31 \%$ of the variability $(F(2,40) 8.84$, $\mathrm{p}<0 \cdot 001$ ).

At 1 year stepwise regression analysis showed that length of stay in hospital was the single predictor that explained $35 \%$ of the variance $(\mathrm{F}(1,39) 21.25$, $\mathrm{p}<0.0001)$. Univariate analyses indicated that postnatal complication scale scores $(\beta=0.374, p .02)$ and social group I (non-manual occupations) $(\beta=0.339$, p.03) were also significant variables. Because postnatal complication scale scores were correlated with length of stay in hospital $(r=-0.579)$ they were again dropped from the multivariate analyses. The coefficient for the social group variable when social group I was coded as 1 , indicated that the babies with fathers in non-manual occupations have general quotients that are estimated to be about $4 \%$ greater than other social groups after statistical adjustment for length of stay in hospital.

\section{Discussion}

At 6 months the developmental progress of the sick babies was comparable with that of the control infants, but at 1 year they were performing significantly less well in almost all areas of development. Developmental quotients were generally within the normal range, but one infant was mentally handicapped and three infants had general quotients that were more than two standard deviations below the mean. The general quotients of all the infants in the control group were within the normal range.

The psychological state of the mother was the best predictor of the sick infants' development at 6 months. Infants with mothers who were experiencing psychological difficulties were more likely to have lower general quotient scores (table 4). The length of stay in hospital (table 5) also seemed to be an important factor and, together with standardised psychiatric interview scores, explained $31 \%$ of the variability in general quotient scores. By the time the babies were 1 year old the most important predictor of the sick infants' developmental progress was the total length of stay in hospital $(35 \%$ of the variance). Another important factor was the severity of the infants' condition in the neonatal period. This was strongly correlated with the length of time an infant spent in hospital, indicating a strong association between these two variables during the first year of life. Parental social group became a relatively important factor at 1 year, babies with parents in 'non-manual occupations being more likely to have higher general quotient scores.

The association between the mothers' psychiatric disturbances and the sick infants' developmental progress indicates that a depressed mother may interact less with her sick infant in the early months. Furthermore it is probable that the sick infants were not as responsive to their parents as normal infants. Interestingly, the developmental progress of infants in the control group was not adversely affected if the mothers had psychological problems. There were no differences between the groups on the ratings of the quality of the marriage, but there was a strong 
Table 4 Developmental quotients at 6 months by mothers' mental health as measured by Goldberg's standardised psychiatric interview

\begin{tabular}{lll}
\hline $\begin{array}{l}\text { Griffiths's scales } \\
\text { Mean }(S D)\end{array}$ & \multicolumn{2}{l}{\begin{tabular}{l} 
Mothers' mental health score groups \\
\cline { 2 - 3 }
\end{tabular}} \\
\cline { 2 - 3 } & $\begin{array}{l}\text { Low score }(<14) \\
(n=33)\end{array}$ & $\begin{array}{l}\text { High score }(\geqslant 14)^{*} \\
(n=10)\end{array}$ \\
\hline General quotient & $101 \cdot 48(7 \cdot 46)$ & $87 \cdot 70(26 \cdot 62)$ \\
Mental age (weeks) & $27 \cdot 91(3 \cdot 2)$ & $24 \cdot 10(9 \cdot 56)$ \\
Motor & $103 \cdot 30(12 \cdot 02)$ & $87 \cdot 40(31 \cdot 63)$ \\
Personal/social & $106 \cdot 88(8 \cdot 79)$ & $91 \cdot 50(29 \cdot 08)$ \\
Hearing/speech & $89 \cdot 61(8 \cdot 80)$ & $77 \cdot 10(20 \cdot 96)$ \\
Eye/hand & $102 \cdot 55(9 \cdot 30)$ & $87 \cdot 30(37 \cdot 06)$ \\
Performance & $105 \cdot 21(12 \cdot 57)$ & $92 \cdot 60(27 \cdot 73)$ \\
\hline
\end{tabular}

${ }^{*}$ Indicative of probable psychiatric illness.

Table 5 Developmental quotients at 1 year by length of stay in hospital $(n=41)$

\begin{tabular}{lll}
\hline $\begin{array}{l}\text { Griffiths's scales } \\
\text { Mean }(S D)\end{array}$ & Length of stay in hospital & \\
\cline { 2 - 3 } & $\begin{array}{l}<8 \text { days } \\
(n=22)\end{array}$ & $\begin{array}{l}\geqslant 28 \text { days } \\
(n=19)\end{array}$ \\
\hline General quotient & $108 \cdot 64(10 \cdot 66)$ & $96 \cdot 32(17 \cdot 23)$ \\
Mental age (weeks) & $58 \cdot 05(5 \cdot 43)$ & $51 \cdot 46(9 \cdot 41)$ \\
Motor & $116 \cdot 45(17 \cdot 93)$ & $98 \cdot 63(28 \cdot 43)$ \\
Personal/social & $105 \cdot 09(7 \cdot 70)$ & $96 \cdot 74(19 \cdot 40)$ \\
Hearing/speech & $100 \cdot 23(10 \cdot 61)$ & $87 \cdot 74(20 \cdot 37)$ \\
Eye/hand & $111 \cdot 14(10 \cdot 63)$ & $99 \cdot 05(14 \cdot 10)$ \\
Performance & $110 \cdot 73(17 \cdot 42)$ & $99 \cdot 21(14 \cdot 68)$ \\
\hline
\end{tabular}

association between maternal depression and poor marriages. This confirms the findings of other studies. ${ }^{14} 15$

The parents of the sick babies were under greater general stress than those of the control group. A stress score was calculated for each family by adding the serious stress factors affecting it. These included stress caused by bereavement, financial difficulties, housing, and problems at work. Stress scores in the 12 months before the birth of the index child were similar for the two groups, but at each subsequent stage of the study the scores were significantly higher in the families with sick babies. These findings suggest that it is a combination of factors rather than just the anxiety associated with the birth of a sick baby that contributes to the increased incidence of maternal depression. Mothers of sick babies may therefore benefit from guidance and support in the months after discharge, which should help to alleviate some of the difficulties experienced by the families and, in so doing, improve their psychological state. This is important, because their babies seem to be more vulnerable to the effects of depression on the mother/infant interactions than do the healthy controls. Moreover, a recent study has shown that maternal depression during the first year of life may have longer term consequences for cognitive development. ${ }^{16}$ An important finding of the present study was that maternal depression was not associated with postpartum separation, nor to the length of the separation caused by the infants' stay in hospital. In addition, length of stay in hospital was not associated with problems in the parental relationship.

Despite the separation of mother and infant and the increased incidence of depression and anxiety in the mothers of the sick infants, the mother/child relationships were generally as loving and secure as those in the control group. Data about the mother/ infant relationships will be reported elsewhere.

In conclusion, our findings indicate that sick babies born at full term are, as a group, developmentally slower at 1 year than a group of healthy babies. The follow up study at 3 years will show whether this effect persists.

This research was supported by grants from the Nuffield Foundation, the University of London, and the Lowe-Costello fund. We thank Mr EM Kiely, Mr RJ Brereton, Dr R Dinwiddie, and Dr D Harvey for allowing us to include their patients in the study, and Mrs A Dawkins (Institute of Education) and Dr M Smith (Institute of Child Health) for statistical advice. We also thank the parents of the infants for participating in the study. 


\section{References}

1 Marlow N, D'Souza SW, Chiswick ML. Neurodevelopmental outcome in babies weighing less than $2001 \mathrm{~g}$ at birth. $\mathrm{Br}$ Med J 1987;294:1582-6.

${ }^{2}$ Hunt JV. Predicting intellectual disorders in childhood for preterm infants with birthweights below $1501 \mathrm{gm}$. In: Friedman SL, Sigman M, eds. Preterm birth and psychological development. New York: Academic Press, 1981.

${ }^{3}$ Ferrari F, Grosoli MV, Fontana G, Cavazzuti GB. Neurobehavioural comparison of low-risk preterm and full term infants at term conceptional age. Dev Med Child Neurol 1983;25:450-8.

4 Fancourt R, Campbell S, Harvey D, Norman AP. Follow-up study of small for dates babies. Br Med J 1976;i:1436-7.

5 Siegal LS. Reproductive, perinatal, and environmental factors as predictors of the cognitive and language development of preterm and full-term infants. Child Dev 1982;53:963-73.

6 Sigman M, Parmelee AH. Longitudinal evaluation of the preterm infant. In: Field T, ed. Infants born at risk. New York: Spectrum Publications, 1979.

7 Cohen SE, Sigman M, Parmelee AH, Beckwith L. Perinatal risk and developmental outcome in preterm infants. Semin Perinatol 1982;6:334-97.

8 Davies PA, Stewart A. Low-birth weight infants: neurological sequelae and later intelligence. Br Med Bull 1975;31:85-91.

9 Littman B, Parmelee AH. Medical correlates of infant development. Pediatrics 1978;61:470-4.
10 Quinton DA, Rutter M, Rowlands O. An evaluation of an interview assessment of marriage. Psychol Med 1976;6:577-86.

11 Goldberg D, Eastwood MR, Kedward HB, et al. A standardized psychiatric interview for use in community surveys. British Journal of Preventive and Social Medicine 1970;24:18-23.

12 Goldberg DF. Manual of the general health questionnaire. Windsor: National Foundation for Educational Research, 1978.

${ }^{13}$ Griffiths R. The abilities of young children. London: Child Development Research Centre, 1970.

14 Watson JP, Elliott AJ, Rugg AJ, Brough DI. Psychiatry disorder in pregnancy and the first postnatal year. $\mathrm{Br} J$ Psychiatry 1984;144:453-62.

15 Cox JL, Connor Y, Kendell RE. Prospective study of the psychiatric disorders of childbirth. Br J Psychiatry 1982;140: 111-7.

16 Cogill SR, Caplan HL, Alexandra H, Robson KM, Kumar R. Impact of maternal postnatal depression on cognitive development of young children. Br Med J 1986;292:1165-7.

Correspondence to Mrs Lorraine Ludman, Department of Child Psychiatry, Hospital for Sick Children, Great Ormond Street, London WC1N 3JH.

Accepted 26 October 1988 